\title{
Mineração
}

\section{Avaliação da presença de monazita em concentrado de ilmenita produzido na mina do Guaju (PB)}

\section{(Evaluation of monazite presence in ilmenite concentrates produced at Guaju mine (PB))}

\author{
Karime Ribeiro e Silva Ferreira \\ Engenheira de Minas, doutoranda, LAPROM/PPGEM/UFRGS \\ E-mail: karime.ferreira@ufrgs.br
}

Sydney Sabedot

Geólogo, Dr. em Engenharia de Minas, Metalúrgica e de Materiais Professor e Pesquisador no UNILASALLE e Pesquisador no LAPROM/UFRGS

E-mail: sabedot@unilasalle.edu.br

Carlos Hoffmann Sampaio

Professor Adjunto do Departamento de Metalurgia/UFRGS

E-mail:sampaio@ufrgs.br

\section{Resumo}

A ilmenita é um mineral fonte de dióxido de titânio, matéria-prima utilizada como pigmento branco na fabricação de tintas e vernizes, principalmente. O concentrado de ilmenita, avaliado nesse estudo, provém da Mina do Guaju, no Estado da Paraíba, operada pela empresa Millennium Inorganic Chemicals do Brasil S/A. Esse concentrado contém monazita, que, mesmo presente em baixa quantidade, é caracterizada como um contaminante indesejado no processo metalúrgico de fabricação do pigmento. Esse estudo avalia a maneira como a monazita está associada no concentrado de ilmenita. Análises com lupa e Microscópio Eletrônico de Varredura indicaram que a monazita se encontra como partículas liberadas no concentrado de ilmenita, em baixíssima concentração.

Palavras-chave: Ilmenita, dióxido de titânio, monazita.

\begin{abstract}
Ilmenite is a mineral that provides titanium dioxide, which is a white pigmented raw material used mainly in the manufacture of inks and varnishes. The ilmenite concentrate, evaluated in this study, comes from the Guaju's Mine, located in the State of Paraíba ,and operated by the company Millennium Inorganic Chemicals of Brazil S/A. This concentrate contains monazite that is an undesirable contaminant, even in small amounts, for the metallurgical process of pigment manufacture. This study evaluates the manner in which monazite is associated in the ilmenite concentrate. Analyses using microscopy and Scanning Electronic Microscopy indicated that monazite is found as free particles in the ilmenite concentrate, in minuscule concentration.
\end{abstract}

Keywords: Ilmenite, titanium dioxide, monazite. 


\section{Introdução}

O dióxido de titânio $\left(\mathrm{TiO}_{2}\right)$ tem sido utilizado em quantidades cada vez maiores como pigmento branco na fabricação, principalmente, de tintas e vernizes, devido ao seu alto índice de refração, opacidade e poder de cobertura. O segundo maior uso é na indústria de papel, na fabricação de papel fotográfico e de todo tipo de papel para impressão, exceto jornal. Outras aplicações são na indústria de plásticos, borrachas para pneus, esmaltes para porcelanas, encerados, revestimentos de paredes e fibra de vidro. Como principal fonte da matéria-prima, destaca-se a ilmenita, que supre cerca de $90 \%$ da demanda mundial de minerais de titânio (Ré \& Marques, 2002). O mineral é composto por ferro e titânio $\left(\mathrm{FeTiO}_{3}\right)$, podendo ser considerado puro com os valores em torno de $53 \%$ de $\mathrm{TiO}_{2}$ e em torno de $47 \%$ de $\mathrm{FeO}$ (Dana, 1969). Devido a sua elevada densidade (4,5 a 5), é caracterizado como um mineral pesado, sendo encontrado em todos os sedimentos detríticos, mas se concentrando, principalmente, em areias de praias, conhecidas como depósitos de areias pretas (Deer e outros, 1966). Nesses tipos de depósitos é comum estar associado com outros minerais pesados, tais como magnetita, granada, monazita, estaurolita, rutilo, zircão e cianita, entre outros (Silva, 2000).

Uma característica importante da ilmenita é sua associação com a monazita, que é um mineral do grupo fosfato mais comum de Elementos Terras Raras (ETR) (Toledo e outros, 2004). A monazita é o principal mineral fonte de óxido de tório em quantidades que podem variar entre 1 e $20 \%$. O tório é radioativo e recebe considerável atenção como principal contaminante dos concentrados de ilmenita (Dana, 1969).

No Brasil, a maior produtora de ilmenita é a empresa Millennium Inorganic Chemicals do Brasil S/A, que contribui com 57,5\% da produção nacional de dióxido de titânio (DNPM, 2005). Sua unidade de lavra, denominada de Mina do Guaju, está localizada no município de Mataraca(PB), onde a ilmenita ocorre disseminada em dunas litorâneas.
A proposta desse estudo é identificar como a monazita se encontra no concentrado de ilmenita, processado na Mina do Guaju. A monazita constitui rejeito indesejável no processo de metalurgia do pigmento, em Camaçari (BA), que a empresa se esforça em diminuir.

\section{Material e métodos}

O material utilizado foi o concentrado de ilmenita enviado pela empresa Millennium, contendo, em média, 54\% de $\mathrm{TiO}_{2}$. Realizaram-se estudos de caracterização mineralógica e análise de inclusões minerais na ilmenita.

Para a caracterização mineralógica, utilizou-se uma lupa binocular com um aumento de 32 vezes. Fez-se a contagem dos grãos presentes, em uma lâmina de vidro, identificando-os e quantificandoos em toda a área delimitada pelo aumento. Foram analisadas cinco amostras e os resultados referem-se à média das mesmas.

Para a análise das inclusões minerais nos grãos de ilmenita, foram preparados corpos-de-prova com cerca de 0,3 $\mathrm{g}$ de grãos, que foram lixados, polidos e metalizados com grafite e ouro, para serem observados em um Microscópio Eletrônico de Varredura (MEV), acoplado a um Espectrômetro de Dispersão de Energia (EDS). O equipamento MEV foi o da marca PHILIPS, modelo XL20 do Laboratório de Metalurgia Física (LAMEF), da Universidade Federal do Rio Grande do Sul (UFRGS), e o outro da marca JEOL, modelo JSM5800, do Centro de Microscopia Eletrônica (CME), também da UFRGS.

\section{Resultados}

\subsection{Caracterização mineralógica}

A Tabela 1 mostra os resultados da caracterização mineralógica do concentrado de ilmenita.

De acordo com os dados da empresa, cerca de $98 \%$ da ilmenita é concentrada na etapa final do processo de se- paração, em separadores magnéticos e eletrostáticos. Os minerais não identificados foram classificados como "outros”.

A separação da monazita no concentrado de ilmenita ocorre, principalmente, durante o primeiro estágio de separação magnética, na planta de concentração. Por ser um mineral fracamente magnético, às vezes não é separado e segue no processo com a ilmenita.

\subsection{Análise de inclusões minerais}

Para as análises de inclusões minerais, procurou-se fazer uma varredura em todos os grãos das amostras preparadas.

A Figura 1 mostra um grão de ilmenita contendo vazios deixados por inclusões minerais arredondadas, bem como o resultado da análise de EDS em um desses vazios.

Em todas as amostras observadas no $\mathrm{MEV}$, apareceram grãos contendo pequenas quantidades de vazios deixados por inclusões minerais arredondadas, como mostradas na Figura 1. O espectro dessa análise apresenta elevados picos de ferro e titânio, que identificam o

Tabela 1 - Caracterização mineralógica do concentrado de ilmenita.

\begin{tabular}{c|c}
\hline Mineral & Composição (\%) \\
\hline Ilmenita & 98,66 \\
\hline Estaurolita & 0,20 \\
\hline Turmalina & 0,08 \\
\hline Zircão & 0,17 \\
\hline Monazita & 0,10 \\
\hline Rutilo & 0,08 \\
\hline Cianita & 0,02 \\
\hline Outros & 0,69 \\
\hline TOTAL & $\mathbf{1 0 0}$ \\
\hline
\end{tabular}


Karime Ribeiro e Silva Ferreira et al.

mineral ilmenita. No mesmo espectro, também se identificou a presença de manganês, que substitui o ferro ferroso da ilmenita, o que é comum. Provavelmente, os vazios devem se originar durante a preparação das amostras, pela remoção das inclusões minerais, nas etapas de lixamento e polimento. Nesse mesmo espectro, são mostrados, também, pequenos picos de carbono, oxigênio e alumínio. A presença do carbono seria devido à utilização de grafite para tornar as amostras condutoras no uso do MEV. O oxigênio é um dos elementos presentes na ilmenita. $\mathrm{O}$ alumínio pode ser de algum mineral contaminante, cujos traços tenham permanecido no vazio deixado pela inclusão.
Ainda analisando os vazios deixados por inclusões minerais (Figura 1), o formato dos mesmos lembra o hábito cristalino da monazita. Mas, mesmo se esta fosse detectada, é provável que não interferisse no resultado do teor final do concentrado de ilmenita, devido os grãos serem de tamanhos muito pequenos. Outros grãos apresentaram, também, estes mesmos vazios e os resultados do EDS mostraram espectros semelhantes ao da Figura 1.

Na Figura 2 é mostrado um grão de ilmenita com algumas inclusões minerais indicadas pelos números 1 e 2 , com seus respectivos resultados da análise de EDS.
Os grandes picos mostrados no espectro da inclusão 1, da Figura 2, indicam ser de um mineral contaminante, composto por fósforo e cálcio; os grandes picos mostrados no espectro da inclusão 2, da mesma figura, indicam ser de um mineral contaminante composto por alumínio e silício. Essas inclusões aparecem com pouca freqüência e suas presenças não afetam o teor final do concentrado de ilmenita.

Na Figura 3, é mostrada uma provável inclusão de zircão com o seu resultado da análise de EDS.

O resultado da análise com EDS (Figura 3) revela a presença do elemento zircônio, indicando tratar-se de uma in-

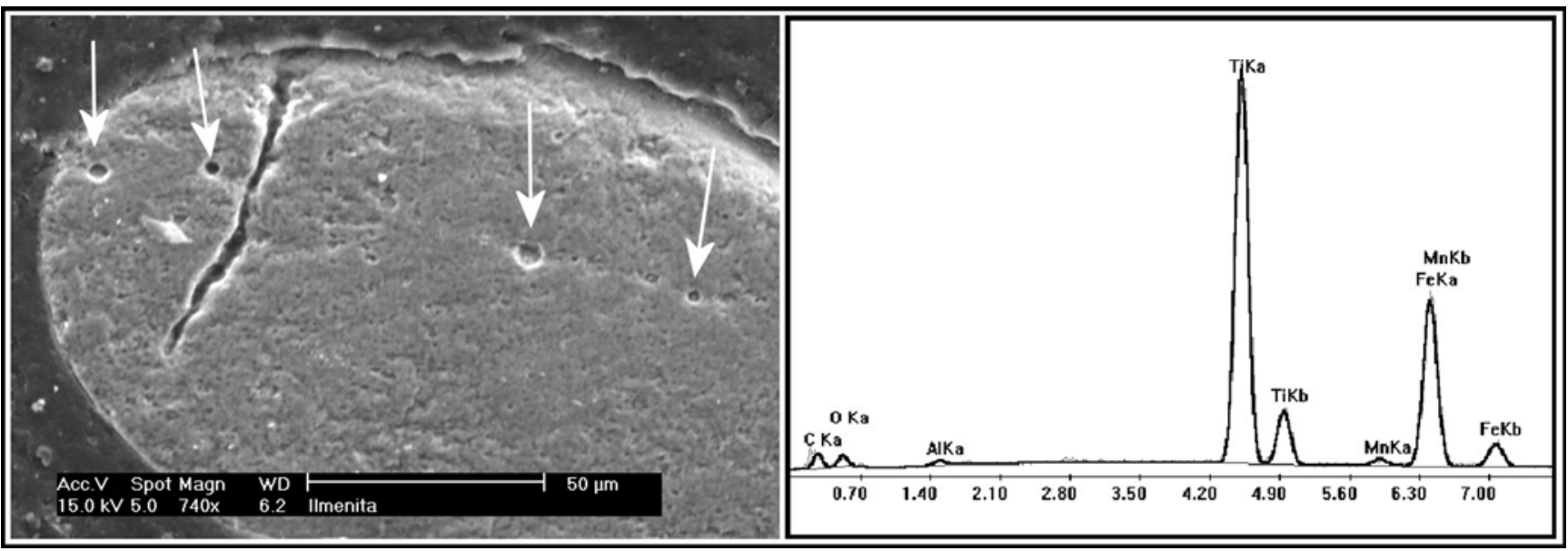

Figura 1 - Imagem MEV de vazios deixados por inclusões minerais arredondadas em um grão de ilmenita e análise de EDS em um vazio.

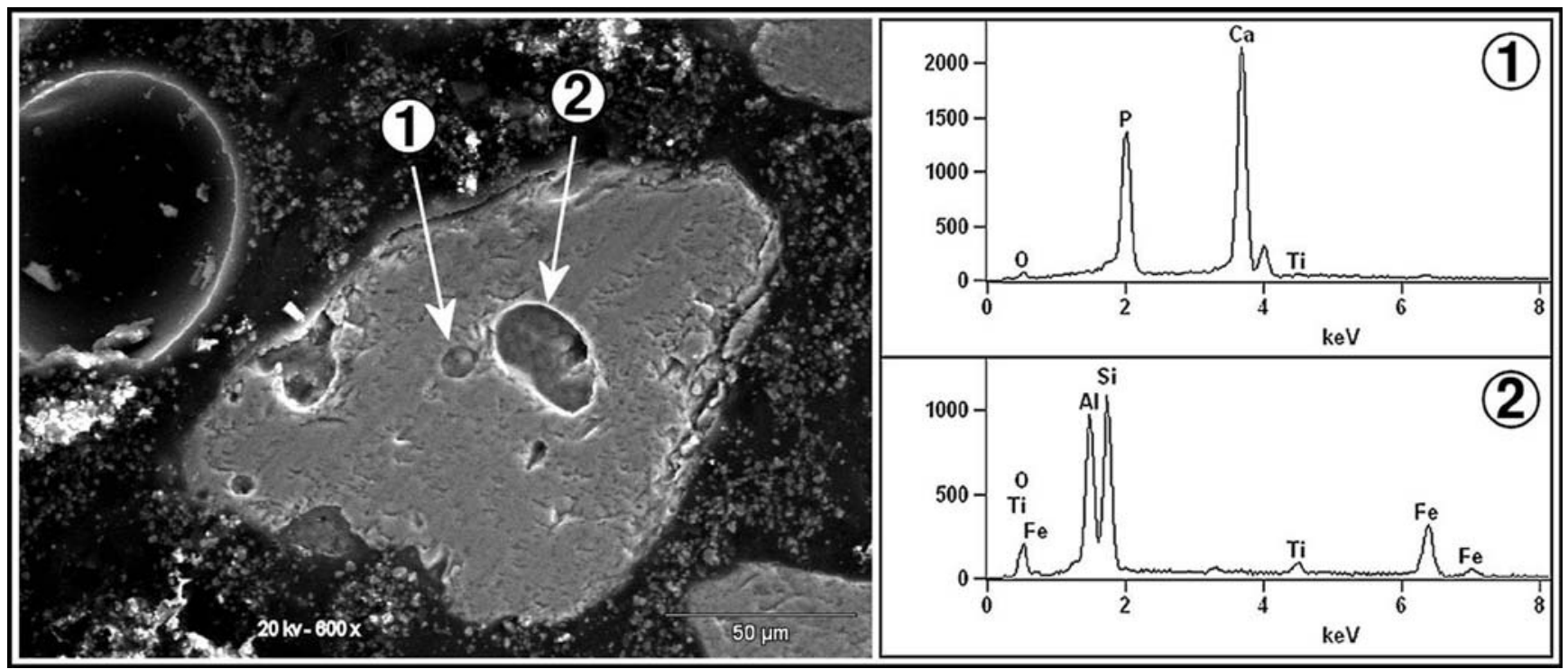

Figura 2 - Imagem MEV de duas inclusões minerais (1 e 2) em um grão de ilmenita com seus respectivos resultados da análise de EDS 


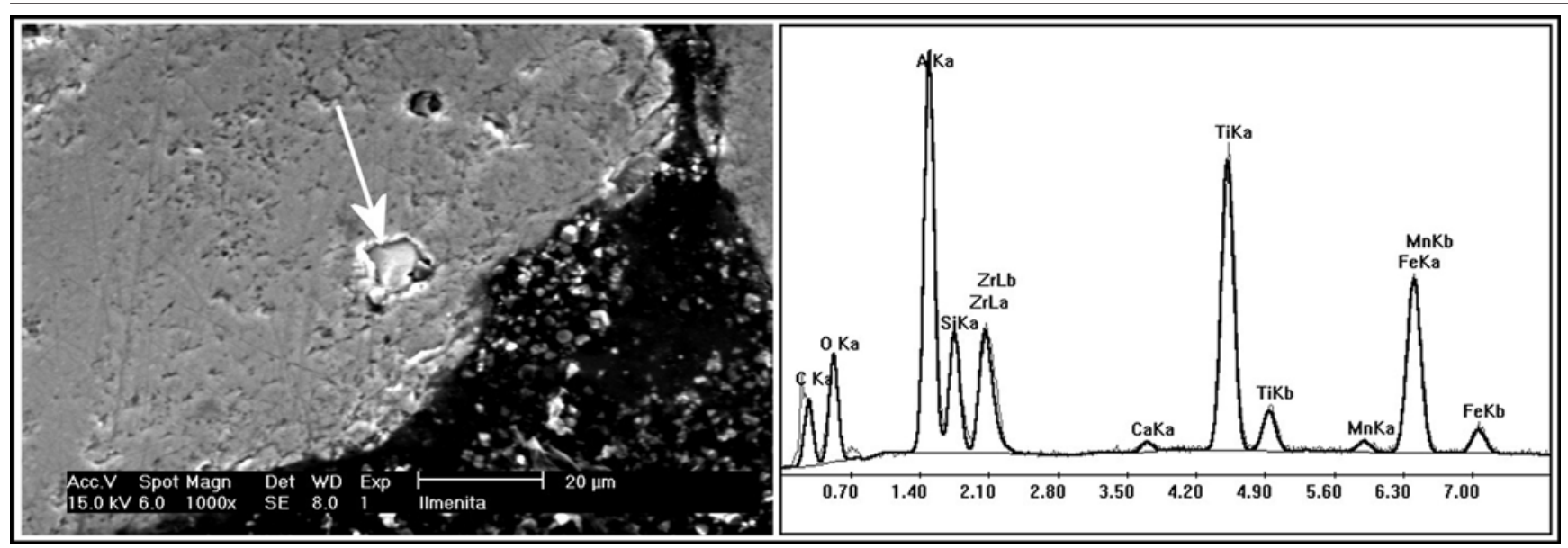

Figura 3 - Imagem MEV de provável inclusão de zircão em um grão de ilmenita, com a análise de EDS.

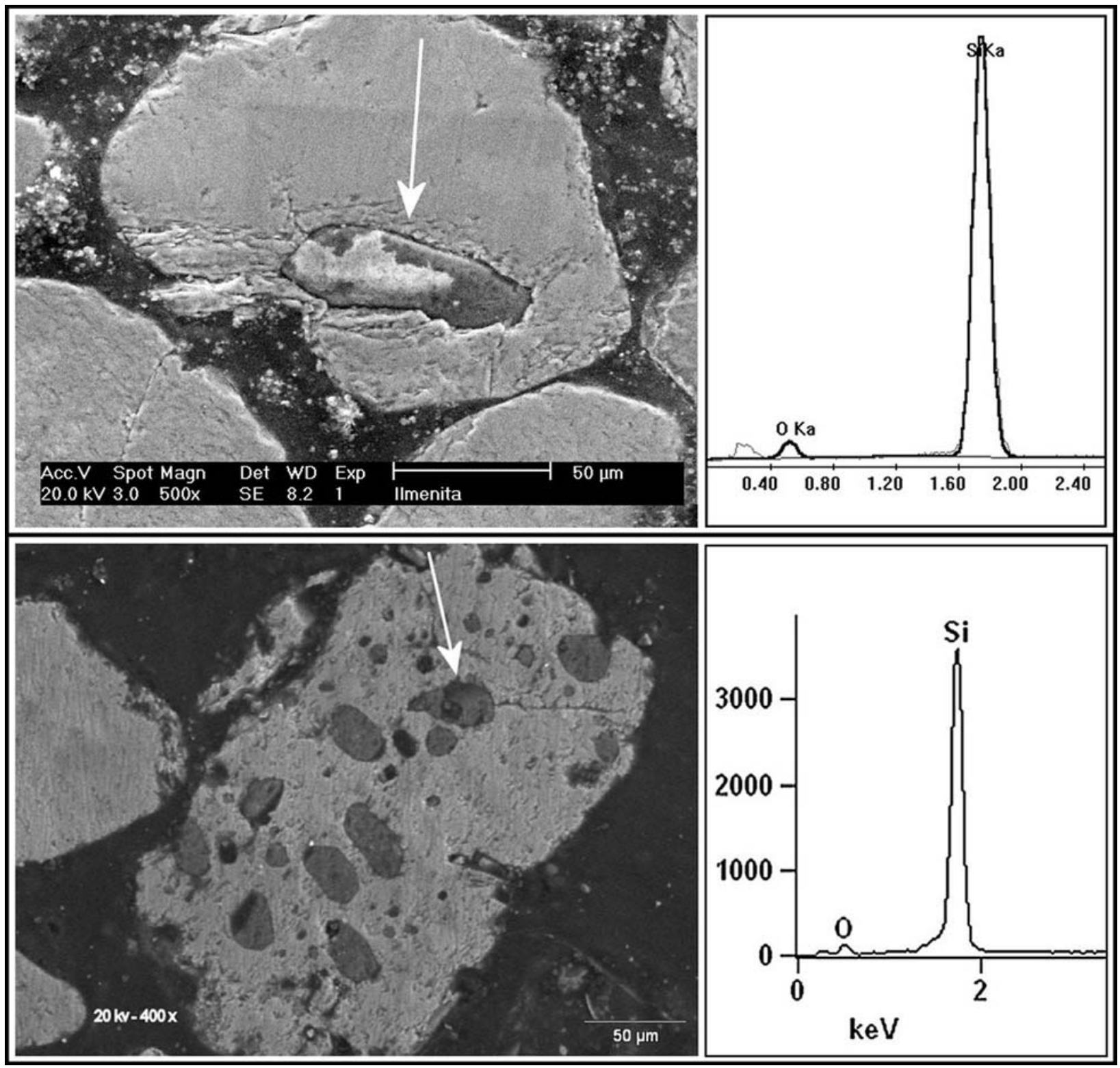

Figura 4 - Imagens MEV de inclusões de quartzo em grãos de ilmenita com as análises de EDS. 
Karime Ribeiro e Silva Ferreira et al.

clusão de zircão. A dimensão dessa inclusão é inferior a $20 \mu \mathrm{m}$, e foram identificadas pouquíssimas inclusões deste tipo nos grãos de ilmenita.

Na Figura 4, são mostrados, em destaque, dois grãos de ilmenita contendo inclusões de quartzo, com seus respectivos resultados das análises de EDS.

O grão de ilmenita, localizado na parte superior da Figura 4, contém uma grande inclusão de quartzo, com dimensão superior a $50 \mu \mathrm{m}$. A análise com EDS mostrou apenas um grande pico de silício e um pequeno pico de oxigênio, que identificam o quartzo. O grão de ilmenita, localizado na parte inferior da Figura 4, contém várias inclusões de quartzo, cujos espectros em EDS mostraram somente picos de silício e oxigênio. Nesse grão, foi destacada apenas uma inclusão com tamanho aproximado de $40 \mu \mathrm{m}$.

\section{Conclusões}

A análise do concentrado de ilmenita em lupa possibilitou identificar a presença de grãos de monazita em pequenas quantidades. Isso indica que a monazita encontra-se liberada e, devido a sua baixa susceptibilidade magnética, segue com a ilmenita nas demais etapas de beneficiamento desse mineral.

Em pequenas quantidades aparecem, também, os minerais estaurolita, turmalina, zircão, rutilo, cianita e outros minerais não identificados. Assim, a presença desses minerais não interfere na qualidade do concentrado. Provavelmente, seguem na rota do processo de concentração da ilmenita durante as etapas de separação magnética e eletrostática.
Nenhuma das amostras visualizadas no MEV apresentou inclusões de monazita, embora algumas evidências, como vazios deixados por inclusões, indicassem a presença do mineral, e que poderiam ter sido arrancadas durante a etapa de lixamento e polimento das amostras. Entretanto, mesmo que fossem identificadas através da análise com EDS, seriam quantidades mínimas que resultariam em baixos teores no concentrado final de ilmenita.

Foram identificadas, também, em alguns grãos de ilmenita, inclusões minerais cujas análises com EDS mostraram ser minerais compostos por fósforo, cálcio, alumínio e silício, bem como zircão. Considerando a quantidade mínima dessas inclusões, é provável que não interferissem no teor final do concentrado de ilmenita.

Quantidades consideráveis de inclusões de quartzo foram encontradas em muitos grãos de ilmenita, porque os picos dos espectros apresentaram somente os elementos silício e oxigênio. Porém, nas quantidades identificadas, esse contaminante não interfere no teor final do concentrado de ilmenita.

\section{Agradecimentos}

Os autores agradecem à empresa Millennium Inorganic Chemicals do Brasil $\mathrm{S} / \mathrm{A}$, por permitir a visita e a estadia na mina, além de disponibilizar as amostras para este estudo; à CAPES, pelo auxílio financeiro.

\section{Referências bibliogáficas}

DANA, J.D. Manual de mineralogia. Rio de Janeiro: Livros Técnicos e Científicos, 1969. p. 669.

DEER, W. A., HOWIE, R.A., ZUSSMAN, J. Minerais constituintes das rochas -uma introdução. London: Longmans, Green and Co., Ltd., 1966. p. 558.

Departamento Nacional de Produção Mineral. Anuário Mineral Brasileiro. Brasília, 2005. Disponível em: <http://www.dnpm.gov.br/ conteudo.asp?DSecao=68\&IDPagina=294> Acesso em: 16 jun. 2006.

RÉ, E.R., MARQUES, M.B. Planejamento de lavra para mineração de minerais pesados para titânio. Workshop Datamine, 10. p. 13, 2002. Disponível em: $<\underline{\text { http:/ }}$ /www.datamine.com.br/arquivos/RicardoRe.pdf> Acesso em: 2 jun. 2006.

SILVA, C.G. Placeres Marinhos. Revista Brasileira de Geofísica, v.18, n.3, p.327-336. São Paulo, 2000.

TOLEDO, M.C.M.de, OLIVEIRA, S.M.B.de, FONTAN, F., FERRARI, V.C. e PARSEVAL, P.de. Mineralogia, morfologia e cristaloquímica da monazita de Catalão I. Revista Brasileira de Geociências, v.34, p.135-146, 2004.

Artigo recebido em 16/01/2007 e aprovado em 27/05/2007.

\section{REM - Revista Escola de Minas www.rem.com.br}

